\title{
EDITORIAL
}

\section{COPD disease progression and airway inflammation: uncoupled by smoking cessation}

\author{
P.W. Ind
}

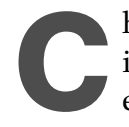
hronic obstructive pulmonary disease (COPD) is an important cause of morbidity, mortality and socioeconomic burden, and its prevalence continues to increase. It is expected to rise from its current position as the fourth to the third most common cause of death, worldwide, by the year 2020 [1]. Cigarette smoking is recognised as the cause of COPD in the vast majority of patients, although it remains a central question in respiratory medicine why a minority (15-20\%) of smokers develop clinical COPD.

Cigarette smoke-induced airway inflammation is thought to play an important pathogenetic role in COPD [2]. It is characterised by neutrophil influx into the airway lumen and by increased numbers of macrophages and T-lymphocytes, particularly CD8+ cells, in the airway wall. Recent studies have emphasised the importance of oligoclonal CD4+ cells [3], Bcells [4] and plasma cells.

Since the pioneering epidemiological studies of FLETCHER and PETO [5], it has been generally accepted that smoking cessation slows the accelerated decline in forced expiratory volume in one second (FEV1), which characterises COPD and usually serves as a surrogate for disease activity. The controlled evidence is obtained from prospective studies, such as the Lung Health Study [6], where FEV1 improved in the first year and the subsequent rate of decline was reduced by $\sim 50 \%$ in sustained "quitters". Intermittent complete abstinence from smoking led to rates of FEV1 decline that were intermediate between sustained quitters and continuing smokers, and only a very substantial reduction in smoking to less than five cigarettes daily was associated with reduced FEV1 decline [7]. In addition, exacerbations appear to be related to decline in FEV1 in smokers, but not in "quitters" [8]. Smoking cessation is associated with less respiratory symptoms and hyperresponsiveness, and a greater increase in bronchodilator response, particularly over the first year, but there was no relationship between bronchodilator response and subsequent FEV1 decline [9]. Consequently, smoking cessation is generally accepted as the only disease-modifying therapy so far available for the management of mild or moderate COPD. It also presents a noninvasive, relevant experiment in understanding the nature and importance of airway and pulmonary inflammation, and there is some evidence of a "dose response" for this intervention.

CORRESPONDENCE: P.W. Ind, NHLI Imperial College, Hammersmith Hospital, Ducane Road, London, W12 0NN, UK. Fax: 44 1817439733. E-mail: p.ind@imperial.ac.uk
In the current issue of the European Respiratory Journal, the paper by WILLEMSE et al. [10] is of major interest in adding to the limited available evidence on airway inflammation and smoking cessation. It is unique in prospectively comparing 12 out of 28 patients with COPD, 16 out of 25 asymptomatic smokers with normal lung function and 4 out of 10 chronic bronchitics, before and after 12 months of smoking cessation. There was no inhaled steroid use. High quit rates were achieved with an intensive 3-month programme and reinforcement. Smoking cessation was verified over the year by four negative urinary cotinine concentrations. The current author's group is very experienced in the examination of induced sputum and bronchial biopsies. Induced sputum total cell count, neutrophils, lymphocytes, interleukin (IL)-8 and eosinophil cationic protein (ECP) levels all increased at 12 months, compared with baseline in COPD quitters. Macrophages (numbers and percentages), eosinophil percentage and IL-8 decreased, and neutrophil percentage increased in asymptomatic smokers after 12 months' abstinence. Significant differences between the two groups were found for total cell concentration, numbers of neutrophils, macrophages and epithelial cells and concentrations of sputum IL-8 and ECP after 12 months' smoking cessation. In bronchial biopsies, mast cells decreased and B-cells increased in asymptomatic smokers with no changes found after quitting in COPD patients. These differences in inflammatory response to smoking cessation suggest perpetuation in COPD, but reduction in some aspects of inflammation in asymptomatic smokers 12 months after quitting smoking. Furthermore, smoking cessation resulted in a slight increase in FEV1 percentage predicted in the COPD patients with no change in asymptomatic smokers.

No study is perfect, and this report can be criticised for the relatively small subject numbers. Some of the data in the COPD group have already been published, but any duplication is justified, in a previous report [11]. This demonstrated improved metacholine (1.6 doubling concentrations) and adenosine monophosphate responsiveness (2.1 doubling concentrations) in COPD patients after 12 months' abstinence. This is not necessarily at variance with the report from the Lung Health Group that responsiveness deteriorates over 5 yrs, albeit to a lesser extent in quitters than continuing smokers [12]. Almost inevitably, there were minor differences between COPD quitters and asymptomatic smokers at baseline. The patients were significantly older and significantly heavier smokers, but the importance of this is unknown. 
Unfortunately, the opportunity to re-examine COPD patients and asymptomatic smokers who were unable to quit was denied by the local ethics committee. These would have been important comparison groups, both as quality control, and also in terms of historical control and progression. The ethical principle involved is opaque. Avoidance of repeat bronchoscopy might be seen as condoning continued smoking. It almost seems unethical not to repeat the measurements in all groups.

In asymptomatic smokers, cross-sectional studies and longitudinal studies [13] suggest that inflammatory changes are at least partially reversible with smoking cessation or even reduction. However, in COPD, cross-sectional studies have so far failed to show differences in bronchial biopsies and sputum between COPD patients who smoke and those who quit [13]. COPD quitters showed more extensive inflammation than asymptomatic ex-smokers with increased mucosal macrophage and eosinophil numbers, sputum neutrophil and sputum and bronchoalveolar lavage eosinophil percentages [14].

The largest cross-sectional bronchial biopsy study, Groningen Leiden Universities and Corticosteroids in Obstructive Lung Disease (GLUCOLD), involved continuing smokers with COPD and patients who quit for $<3.5$ yrs and $>3.5$ yrs [15]. Ex-smokers had increased numbers of CD3+, CD4+ and CD138+ plasma cells compared with continuing smokers taking sex, age and FEV1/vital capacity differences into account. Short-term ex-smokers had higher CD4+ and CD8+ cell numbers compared with current smokers, but longer-term quitters had lower CD8+ than short-term quitters and lower CD8+/CD3+ ratios compared with continuing smokers and recent quitters.

In small numbers of patients, pulmonary inflammation has been assessed noninvasively using positron emission tomography and ${ }^{18}$ F-fluorodeoxyglucose uptake. In six patients with COPD who had stopped smoking, inflammatory cell activity (putatively neutrophils) was increased compared with normal subjects [16]. In further unpublished studies, the signal was similar in smoking and ex-smoking patients.

There seems little doubt (although confirmation from other groups is required) that smoking cessation leads to the reversal of the inflammatory changes in asymptomatic smokers, while no improvement in measured parameters of inflammation is observed in smokers with COPD who quit. This difference is made all the more cogent by the improvement in FEV1 decline seen on smoking cessation in different grades of COPD. This suggests that not only does the inflammation measured become self-perpetuating (which could be related to latent adenovirus or bacterial colonisation, auto-immune induction [17] or persistent apoptosis [18]), but that it does not necessarily contribute substantially to at least one of the main features of disease progression. The exciting "auto-immune hypothesis" [17], which has gathered further support [3, 19], does not really explain this discrepancy beyond the involvement of multiple types of inflammation triggered by smoking. Inflammation is too loose a term, and we should specify exactly which features are concerned whenever we mention it. Probably some inflammation is a consequence of airway disease rather than a cause. As WILLEMSE et al. [10] point out, what is measured could, in part, reflect persistent attempts to repair the lung damage caused by smoking in COPD or result from bacterial colonisation (which itself may relate to increased airway inflammation in COPD with frequent exacerbations).

Corticosteroid-responsive inflammation appears to not only involve eosinophils, but is also associated with decreased symptoms and reduced exacerbations of severe disease, with some evidence of reduced CD8:CD4 ratio and subepithelial mast cell numbers [20]. However, unlike smoking cessation, it is not associated with a reduced forced expiratory volume in one second decline [21]. A key target of chronic obstructive pulmonary disease research remains a novel anti-inflammatory agent, which mimics smoking cessation in suppressing forced expiratory volume in one second decline, and which would further define the different components of inflammation in chronic obstructive pulmonary disease.

\section{REFERENCES}

1 Murray CJL, Lopez AD. Mortality by cause for eight regions of the world: Global Burden of Disease Study. Lancet 1997; 349: 1269-1276.

2 Global initiative for Chronic Obstructive Lung Disease. Global strategy for the Diagnosis, Management and Prevention of Chronic Obstructive Pulmonary Disease. NHLBI/WHO workshop report, 2005. www.goldcopd. com. Date last accessed: September 7, 2005. Date last updated: 2005.

3 Sullivan AK, Simonian PL, Falta MT, et al. Oligoclonal CD4+ $\mathrm{T}$ cells in the lungs of patients with severe emphysema. Am J Respir Crit Care Med 2005; 172: 590-596.

4 Hogg JC, Chu F, Utokaparch S, et al. The nature of smallairway obstruction in chronic obstructive pulmonary disease. N Engl J Med 2004; 350: 2645-2653.

5 Fletcher C, Peto R. The natural history of chronic airflow obstruction. BMJ 1977; 1: 1645-1648.

6 Anthonisen NR, Connett JE, Kiley JP, et al. Effects of an inhaled anticholinergic bronchodilator on the rate of decline in FEV1. JAMA 1994; 272: 1497-1505.

7 Simmons MS, Connett JE, Nides MA, et al. Smoking reduction and the rate of decline in FEV1: results from the Lung Health Study. Eur Respir J 2005; 25: 1011-1017.

8 Kanner RE, Anthonisen NR, Connett JE. Lower respiratory illnesses promote FEV1 decline in current smokers but not exsmokers with mild chronic obstructive pulmonary disease. Am J Respir Crit Care Med 2001; 164: 358-364.

9 Anthonisen NR, Lindgren PG, Tashkin DP, et al. Bronchodilator response in the lung health study over 11 years. Eur Respir J 2005; 26: 45-51.

10 Willemse BWM, ten Hacken NHT, Rutgers B, LesmanLeegte IGAT, Postma DS, Timens W. Effect of 1-year smoking cessation on airway inflammation in COPD and asymptomatic smokers. Eur Respir J 2005; 26: 835-845.

11 Willemse BW, ten Hacken NH, Rutgers B, et al. Smoking cessation improves both direct and indirect airways hyperresponsiveness in COPD. Eur Respir J 2004; 24: 391-396. 
12 Wise RA, Kanner RE, Lindgren $\mathrm{P}$, et al. The effect of smoking intervention and an inhaled bronchodilator on airways reactivity in COPD, the Lung Health Study. Chest 2003; 124: 449-458.

13 Willemse BW, Postma DS, Timens W, et al. The impact of smoking cessation on respiratory symptoms, lung function, airways hyperresponsiveness and inflammation. Eur Respir J 2004; 23: 464-476.

14 Rutgers SR, Postma DS, ten Hacken NH, et al. Ongoing airway inflammation in patients with COPD who do not currently smoke. Thorax 2000; 55: 12-18.

15 Laperre TS, Postma DS, Gosman MM, et al. Relation between duration of smoking cessation and bronchial inflammation in COPD. Thorax 2005; Epub ahead of print.

16 Jones HA, Marino PS, Shakur BH, Morrell NW. In vivo assessment of lung inflammatory cell activity in patients with COPD and asthma. Eur Respir J 2003; 21: 567-573.
17 Agusti A, MacNee W, Donalson K, Cosio M. Hypothesis: does COPD have an autoimmune component? Thorax 2003; 58: 832-834.

18 Hodge S, Hodge G, Holmes M, et al. Increased airway epithelial and T-cell apoptosis in COPD remains despite smoking cessation. Eur Respir J 2005; 25: 447-454.

19 Cosio MG. Autoimmunity, T-cells and STA-4 in the pathogenesis of chronic obstructive pulmonary disease. Eur Respir J 2004; 24: 3-5.

20 Hattotuwa KL, Gizycki MJ, Ansari TW, et al. The effects of inhaled fluticasone on airway inflammation in chronic obstructive pulmonary disease. A double-blind, placebocontrolled biopsy study. Am J Respir Crit Care Med 2002; 165: 1592-1596.

21 Pauwels RA, Lofdahl C-G, Laitinen LA, et al. Long-term treatment with inhaled budesonide in persons with mild chronic obstructive pulmonary disease who continue smoking. N Engl J Med 1999; 340: 1948-1953. 